\title{
Recent advances on anti-angiogenesis receptor tyrosine kinase inhibitors in cancer therapy
}

\author{
Shuang Qin ${ }^{1+}$, Anping $\mathrm{Li}^{2 \dagger}$, Ming $\mathrm{Yi}^{1}$, Shengnan $\mathrm{Yu}^{1}$, Mingsheng Zhang ${ }^{1}$ and Kongming $\mathrm{Wu}^{1,2^{*}}$ (D)
}

\begin{abstract}
Angiogenesis has always been the topic of major scientific interest in the field of malignant tumors. Nowadays, targeting angiogenesis has achieved success in various carcinomas by several mechanisms, including the use of anti-angiogenic small molecule receptor tyrosine kinase inhibitors (TKIs). The development of TKIs targeting proangiogenic receptors, mainly vascular endothelial growth factor receptor (VEGFR) family, have significantly improved the outcome of certain types of cancers, like renal cell carcinoma, hepatocellular carcinoma, and colorectal carcinoma. However, the general response rate is not very satisfactory. The particular toxicity profile and resistance to anti-angiogenic targeted agents are unavoidable, and no specific marker is available to screen responsive patients to TKls for precision therapy. To date, about 11 anti-angiogenic TKIs with different binding capacities to angiogenic receptor tyrosine kinase have been approved for the treatment of patients with advanced cancers. This review presents all approved antiangiogenic small molecule receptor TKIs so far with an emphasis on their indications and clinical efficacy. We also discuss the combination between TKls and immune checkpoint blockade inhibitors based on the most recent exciting outcome in immunotherapy.
\end{abstract}

Keywords: Anti-angiogenic, Tyrosine kinase inhibitors, VEGF, Immunotherapy

\section{Background}

As described by Hanahan and Weinberg, tumor angiogenesis is regarded as one of the ten hallmarks of cancer [1]. Neovasculature supplies tumor with essential nutrients and oxygen and removes waste produce especially for those whose size is larger than 1-2 mm [2]. Based on the theory that tumor growth, progression, and metastasis depend on angiogenesis, targeting tumor blood vessels has been introduced as a logical approach to the treatment of various malignancies [3]. Subsequently, enormous innovative anti-angiogenic agents have been developed and tested in clinical trials.

In physiological circumstances, angiogenesis is under a relatively dynamic homeostasis, tightly controlled by pro-angiogenic and anti-angiogenic regulators. In cancer,

\footnotetext{
* Correspondence: kmwu@tjh.tjmu.edu.cn

${ }^{+}$Shuang Qin and Anping Li contributed equally to this work.

'Department of Oncology, Tongji Hospital of Tongji Medical College, Huazhong University of Science and Technology, 1095 Jiefang Avenue, Wuhan 430030, Hubei, China

${ }^{2}$ Department of Oncology, The First Affiliated Hospital of Zhengzhou

University, Zhengzhou 450052, Henan, China
}

however, the balance of pro- and anti-angiogenic are disturbed, leading to the switch to angiogenesis [4]. Tumor angiogenesis is an intricate mechanism regulated by multiple signaling pathways. Certain well-known pro-angiogenic factors include vascular endothelial growth factor (VEGF) [5], angiopoietin (ANGPT) [6], basic fibroblast growth factor (bFGF) [7], and platelet-derived growth factor (PDGF) [8], while endogenous anti-angiogenic factors encompass endostatin [9], angiostatin [10], and so on. In the past few decades, the efforts to develop anti-angiogenic treatment mainly focus on inhibiting VEGF/VEGFR signaling pathway such as anti-VEGF antibody bevacizumab [11] and anti-VEGFR2 antibody ramucirumab [12]. Anti-VEGF/ VEGFR single-target drugs often lead to transient responses; however, tumor progression happens because other pathways, such as the PDGF/ PDGFR, FGF/FGFR, and ANGPT/Tie-2, provide potential escape mechanisms [13]. Anti-angiogenic agents inhibiting multiple signaling pathways seem more promising; therefore, multiple pan-target agents have been developed [13].

(c) The Author(s). 2019 Open Access This article is distributed under the terms of the Creative Commons Attribution 4.0 International License (http://creativecommons.org/licenses/by/4.0/), which permits unrestricted use, distribution, and reproduction in any medium, provided you give appropriate credit to the original author(s) and the source, provide a link to the Creative Commons license, and indicate if changes were made. The Creative Commons Public Domain Dedication waiver (http://creativecommons.org/publicdomain/zero/1.0/) applies to the data made available in this article, unless otherwise stated. 
The binding of ligand to its receptor, for instance, VEGF and VEGFR, initiates the activity of tyrosine kinase domain of receptor and upregulates the downstream signal system. Those kinases are often upregulated in cancer and regarded as attractive therapeutic candidates. By April 2017, among the 35 protein kinase inhibitors (PKIs) approved, 31 are used in cancer therapy [14]. For example, sorafenib, sunitinib, and pazopanib are approved anti-angiogenic small molecule tyrosine kinase inhibitors (TKIs). Several novel anti-angiogenic TKIs with promising preclinic outcome are being studied in phase III clinical trials. Furthermore, new advance on combination of immunotherapy and TKIs attracts attention for superior efficacy.

\section{Receptor tyrosine kinases and anti-angiogenic small molecule receptor TKIs}

There are 518 protein kinases encoded in the human genome, of which 90 kinases belong to the group of tyrosine kinases, being a major subclass of the human protein kinases $[15,16]$. The tyrosine kinase group can be classified in receptor tyrosine kinases (RTKs) and non-receptor tyrosine kinases (nRTKs), and the former exerts function on the transduction of extracellular signals into the cell while the latter accomplishes intracellular communication [17]. RTKs share a great degree of similarity in their molecular structure, with an extracellular domain which can bind specific ligands, a single trans-membrane helix, and an intracellular region which contain a protein tyrosine kinase domain [18]. The intracellular domain, also called kinase domain, which is a bi-lobar structure, is composed of an N-terminal lobe, a C-terminal lobe, and an adenosine triphosphate (ATP) binding cleft located between them [19]. Ligand binding to the extracellular domain induces dimerization and allows auto-phosphorylation of the intracellular domains and activation of the receptor's tyrosine kinase [20]. RTKs catalyze the transfer of the phosphates of ATP to the hydroxyl group of tyrosine residues on target proteins [21]. The RTK family includes the insulin receptor and the receptors for many growth factor families such as VEGF, FGF, PDGF, and epidermal growth factor

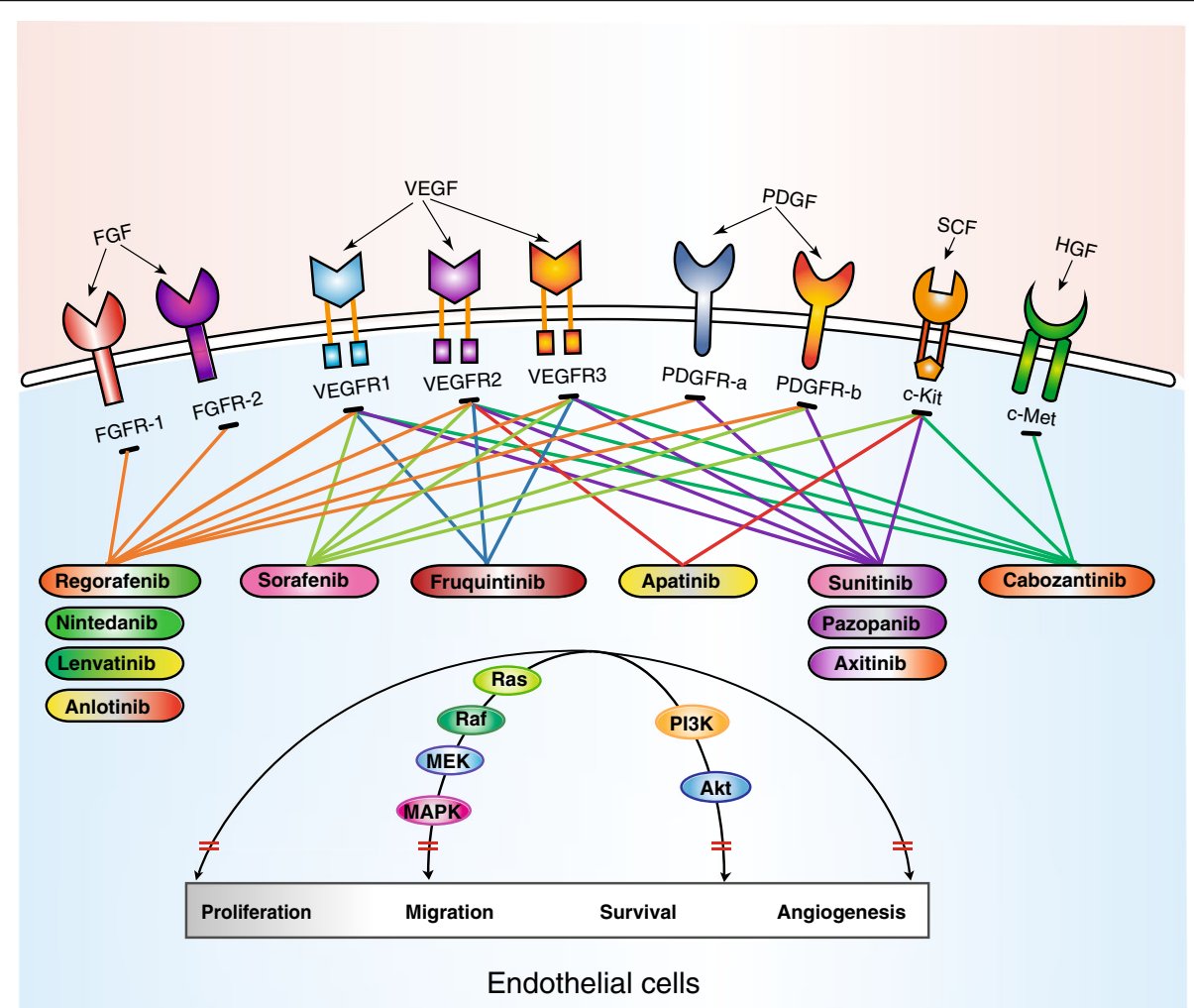

Fig. 1 Main targets of approved anti-angiogenic receptor tyrosine kinase inhibitors (TKIs). All approved anti-angiogenic receptor TKls can target multiple receptor sites simultaneously. The main targets included vascular endothelial growth factor receptor (VEGFR), platelet-derived growth factor receptor (PDGFR), fibroblast growth factor receptor (FGFR), c-Kit, and c-Met. Anti-angiogenic TKls block the kinase activity of receptor and transduction of downstream signal involved in the proliferation, migration, and survival 
(EGF) [21]. The VEGF-related gene family comprises six secreted proteins, namely VEGF-A, VEGF-B, VEGF-C, VEGF-D, VEGF-E, and placenta growth factor (PIGF) [22], and the VEGFR family consists of three related RTKs, VEGFR-1, VEGFR-2, and VEGFR-3 (Fig. 1) [23]. VEGF-A is the most important mediator, mediating its effects by binding to its two high-affinity RTKs: VEGFR-1 and VEGFR-2. PDGFs are the second important growth factor related to angiogenesis. There are at least four members in the PDGF family, namely PDGF-A, PDGF-B, PDGF-C, and PDGF-D. PDGFs act via two RTKs, known as PDGFR- $\alpha$ and PDGFR- $\beta$ [24]. Meanwhile, bFGF, belonging to the FGF family, also contribute to angiogenesis [25]. The binding of ligand to its corresponding receptor initiates phosphorylation of the RTKs and leads to the activation of downstream signaling pathways, such as the PI3K/Akt and Ras/Raf/MEK/ MAPK, which are involved in the proliferation, migration, and apoptosis of endothelial cells [26]. Therefore, small molecule inhibitors of RTKs are regarded as rational targets for cancer therapy.

\section{Approved anti-angiogenic receptor TKIs}

Currently, angiogenic TKIs approved to cancer treatment by the US Food and Drug Administration (FDA) or China Food and Drug Administration (CFDA) are listed in Table 1.

\section{Sorafenib}

Sorafenib is the first anti-angiogenic receptor TKI, targeting VEGFR-1/2/3, PDGFR- $\beta$, and c-Kit receptor. It was initially approved for the treatment of advanced renal cell carcinoma (RCC) based on a phase III, randomized, double-blind clinical trial [27]. As many as 903 patients who are resistant to standard therapy were randomly assigned into two groups: sorafenib or placebo. The study demonstrated a significant improvement in median progression-free survival (PFS) in sorafenib group compared with placebo group (5.5 vs. 2.8 months, $p<0.001$ ), and the partial response was elevated from $2 \%$ to $10 \%(p<0.001)$ [27]. The medium overall survival (OS) demonstrated a reduced risk of death among patients receiving sorafenib though a statistics discrepancy did not reach. The approval of sorafenib by the FDA in 2007 in advanced hepatocellular carcinoma (HCC) was based on the result of SHARP trial [28]. It demonstrated that both the median OS and time to radiologic progression were nearly 3 months longer in sorafenib group than that in placebo group. Now, sorafenib is recognized as a standard treatment for patients with advanced HCC. Sorafenib also showed antitumor activity in differentiated thyroid cancer (DTC). The FDA approved sorafenib in radioactive iodine (RAI) refractory DTC in November 2013 based on the encouraging results of DECISION trial [29], and it was the first target therapy for this type of cancer. A total of 417 patients were enrolled and randomly assigned to sorafenib group or placebo group. PFS was significantly improved in sorafenib arm compared with placebo arm while the OS showed no significant difference in these two groups. Adverse events (AEs) related to sorafenib in these three kinds of carcinomas were similar, mainly including diarrhea, fatigue, desquamation, and hand-foot skin reaction [27-29]. Sorafenib in combine with gemcitabine acquired a favorable result for advanced pancreatic cancer in a phase I trial but failed to demonstrate positive result in phase III trial [30].

\section{Sunitinib}

Sunitinib, the second approved anti-angiogenic receptor TKI, binds to VEGFR-1/2/3, PDGFR- $\alpha / \beta$, c-Kit receptor, Fms-like tyrosine kinase-3 receptor (FLT-3), and receptor encoded by the ret proto-oncogene (Ret) [31]. It was the first cancer drug simultaneously approved by the FDA for two different indications: imatinib-resistant gastrointestinal stromal tumor (GIST) and RCC. In the pivotal phase III study, advanced GIST patients who failed imatinib therapy were treated in a randomized and blinded fashion with either sunitinib or placebo [32]. The result revealed a prolongation of time to progression from 6.4 weeks to 27.3 weeks $(p<0.0001)$, and the objective response rate (ORR), although relatively low, was significantly higher in the sunitinib than that in the placebo group ( $7 \%$ vs. $0 \%, p=0.006$ ) [32]. Additionally, OS obtained from initial sunitinib treatment was better than the placebo group. The landmark trial of sunitinib as a standard of care for first-line advanced RCC was the phase III study of sunitinib versus interferon alfa-2a reported in 2007, in which the superiority of sunitinib in terms of response rate, PFS, and OS were reported [33, 34]. The most common side effects related to sunitinib were diarrhea, fatigue, nausea, and skin discoloration in these two kinds of carcinoma [32, 34]. Beyond that, in May 2011, the FDA approved sunitinib for treating patients with advanced progressive pancreatic neuroendocrine tumors (pNETs) based on the results of a phase III study [35]. The study was terminated early on account of the notable better outcome in sunitinib group with the consent of the Independent Data Committee. The PFS was longer in the sunitinib group than that of the placebo group ( 11.4 vs. 5.5 months, $p<0.001)$, and the ORR was higher in the sunitinib group $(9.3 \%$ vs. $0 \%$, $p<0.007)$. Though the median OS was not reach at the cutoff point, the HR is in favor of sunitinib [35].

\section{Pazopanib}

Pazopanib is a multi-kinase inhibitor on VEGFR-1/2/3, PDGFR- $\alpha / \beta$, and $c-K i t$ receptor [36]. The study VEG105192 conducted by Sternberg et al. compared pazopanib to placebo in 435 advanced RCC patients [37]. The results indicated pazopanib significantly 
Table 1 Principal clinical trials for the approval of anti-angiogenesis receptor tyrosine kinase inhibitors (TKls)

\begin{tabular}{|c|c|c|c|c|c|c|c|}
\hline Drug (company) & Indication & Pivotal study & Study design & PFS & OS & ORR & $\begin{array}{l}\text { Approva } \\
\text { time }\end{array}$ \\
\hline \multirow[t]{3}{*}{$\begin{array}{l}\text { Sorafenib } \\
\text { (Bayer and Onyx) }\end{array}$} & $\mathrm{RCC}$ & NCT00073307 [27] & Phase III, sorafenib vs. placebo & $\begin{array}{l}\mathrm{HR}=0.44 \\
p<0.01\end{array}$ & $\begin{array}{l}\mathrm{HR}=0.77 \\
p=0.02\end{array}$ & $10 \%$ vs. $2 \%$ & $\begin{array}{l}2005 \\
\text { (FDA) }\end{array}$ \\
\hline & $\mathrm{HCC}$ & NCT00105443 [28] & Phase III, sorafenib vs. placebo & $\begin{array}{l}H R=0.58 \\
p<0.001\end{array}$ & $\begin{array}{l}H R=0.69 \\
p<0.001\end{array}$ & $2 \%$ vs. $1 \%$ & $\begin{array}{l}2007 \\
\text { (FDA) }\end{array}$ \\
\hline & DTC & NCT00984282 [29] & Phase III, sorafenib vs. placebo & $\begin{array}{l}\mathrm{HR}=0.59 \\
p<0.0001\end{array}$ & $\begin{array}{l}H R=0.80 \\
p=0.14\end{array}$ & $\begin{array}{l}12.2 \% \text { vs. } \\
0.5 \%\end{array}$ & $\begin{array}{l}2013 \\
\text { (FDA) }\end{array}$ \\
\hline \multirow[t]{3}{*}{$\begin{array}{l}\text { Sunitinib } \\
\text { (Pfizer) }\end{array}$} & GIST & NCT00075218 [32] & Phase III, sunitinib vs. placebo & $\begin{array}{l}H R=0.33 \\
p<0.0001\end{array}$ & $\begin{array}{l}H R=0.49 \\
p=0.007\end{array}$ & $7 \%$ vs. $0 \%$ & $\begin{array}{l}2007 \\
\text { (FDA) }\end{array}$ \\
\hline & $\mathrm{RCC}$ & $\begin{array}{l}\text { NCT00098657 } \\
\text { NCT00083889 }[33,34]\end{array}$ & Phase III, sunitinib vs. INF-a & $\begin{array}{l}\mathrm{HR}=0.42 \\
p<0.001\end{array}$ & $\begin{array}{l}\mathrm{HR}=0.82 \\
p=0.05\end{array}$ & $31 \%$ vs. $6 \%$ & $\begin{array}{l}2007 \\
\text { (FDA) }\end{array}$ \\
\hline & pNETs & NCT00428597 [35] & Phase III, sunitinib vs. placebo & $\begin{array}{l}H R=0.42 \\
p<0.001\end{array}$ & NA & $9.3 \%$ vs. $0 \%$ & $\begin{array}{l}2011 \\
\text { (FDA) }\end{array}$ \\
\hline \multirow[t]{2}{*}{$\begin{array}{l}\text { Pazopanib } \\
\text { (GlaxoSmith Kline) }\end{array}$} & $\mathrm{RCC}$ & NCT00720941 [37] & Phase III, pazopanib vs. placebo & $\begin{array}{l}\mathrm{HR}=0.46 \\
p<0.0001\end{array}$ & NA & $30 \%$ vs. $3 \%$ & $\begin{array}{l}2009 \\
\text { (FDA) }\end{array}$ \\
\hline & STS & NCT00753688 [42] & Phase III, pazopanib vs. placebo & $\begin{array}{l}\mathrm{HR}=0.31 \\
p<0.0001\end{array}$ & $\begin{array}{l}H R=0.86 \\
p=0.25\end{array}$ & $9 \%$ vs. $0 \%$ & $\begin{array}{l}2012 \\
\text { (FDA) }\end{array}$ \\
\hline Axitinib (Pfizer) & $\mathrm{RCC}$ & NCT00678392 [43, 44] & Phase III, axitinib vs. sorafenib & $\begin{array}{l}H R=0.67 \\
p<0.0001\end{array}$ & $\begin{array}{l}\mathrm{HR}=0.97 \\
p=0.37\end{array}$ & $19 \%$ vs. $9 \%$ & $\begin{array}{l}2012 \\
\text { (FDA) }\end{array}$ \\
\hline \multirow[t]{4}{*}{$\begin{array}{l}\text { Regorafenib } \\
\text { (Bayer) }\end{array}$} & CRC & NCT01103323 [47] & Phase III, regorafenib vs. placebo & $\begin{array}{l}H R=0.49 \\
p<0.0001\end{array}$ & $\begin{array}{l}H R=0.77 \\
p=0.005\end{array}$ & $\begin{array}{l}1.0 \% \text { vs. } \\
0.4 \%\end{array}$ & $\begin{array}{l}2012 \\
\text { (FDA) }\end{array}$ \\
\hline & & NCT01584830 [48] & Phase III, regorafenib vs. placebo & $\begin{array}{l}H R=0.31 \\
p<0.0001\end{array}$ & $\begin{array}{l}\mathrm{HR}=0.55 \\
p=0.0002\end{array}$ & $4 \%$ vs. $0 \%$ & \\
\hline & GIST & NCT01271712 [49] & Phase III, regorafenib vs. placebo & $\begin{array}{l}H R=0.27 \\
p<0.0001\end{array}$ & $\begin{array}{l}H R=0.77 \\
p=0.199\end{array}$ & $\begin{array}{l}4.5 \% \text { vs. } \\
1.5 \%\end{array}$ & $\begin{array}{l}2013 \\
\text { (FDA) }\end{array}$ \\
\hline & $\mathrm{HCC}$ & NCT01774344 [50] & Phase III, regorafenib vs. placebo & $\begin{array}{l}\mathrm{HR}=0.46 \\
p<0.0001\end{array}$ & $\begin{array}{l}\mathrm{HR}=0.63 \\
p<0.0001\end{array}$ & $11 \%$ vs. $4 \%$ & $\begin{array}{l}2017 \\
\text { (FDA) }\end{array}$ \\
\hline \multirow[t]{2}{*}{$\begin{array}{l}\text { Cabozantinib } \\
\text { (Exelixis) }\end{array}$} & MTC & NCT00704730 [53] & Phase III, cabozantinib vs. placebo & $\begin{array}{l}H R=0.28 \\
p<0.001\end{array}$ & $H R=0.98$ & $28 \%$ vs. $0 \%$ & $\begin{array}{l}2012 \\
\text { (FDA) }\end{array}$ \\
\hline & $\mathrm{RCC}$ & NCT01865747 [55, 56] & Phase III, cabozantinib vs. everolimus & $\begin{array}{l}H R=0.58 \\
p<0.001\end{array}$ & $\begin{array}{l}H R=0.66 \\
p=0.0003\end{array}$ & $21 \%$ vs. $5 \%$ & $\begin{array}{l}2016 \\
\text { (FDA) }\end{array}$ \\
\hline \multirow{3}{*}{$\begin{array}{l}\text { Nintedanib } \\
\text { (Boehringer) }\end{array}$} & IPF & NCT00514683 [60] & Phase II, nintedanib vs. placebo & NA & NA & NA & 2014 \\
\hline & & $\begin{array}{l}\text { NCT01335464 } \\
\text { NCT01335477 [61] }\end{array}$ & Phase III, nintedanib vs. placebo & & & & \\
\hline & $\mathrm{NSCLC}$ & NCT00805194 [63] & $\begin{array}{l}\text { Phase III, docetaxel + nintedanib vs. } \\
\text { docetaxel + placebo }\end{array}$ & $\begin{array}{l}\mathrm{HR}=0.79 \\
p=0.0019\end{array}$ & $\begin{array}{l}\mathrm{HR}=0.94 \\
p=0.27\end{array}$ & $\begin{array}{l}4.4 \% \text { vs. } \\
3.3 \%\end{array}$ & $\begin{array}{l}2014 \\
(\text { EMA) }\end{array}$ \\
\hline \multirow[t]{3}{*}{$\begin{array}{l}\text { Lenvatinib } \\
\text { (Eisai ) }\end{array}$} & DTC & NCT01321554 [67] & Phase III, lenvatinib vs. placebo & $\begin{array}{l}H R=0.21 \\
p<0.001\end{array}$ & $\begin{array}{l}\mathrm{HR}=0.73 \\
p=0.10\end{array}$ & $\begin{array}{l}64.8 \% \text { vs. } \\
1.5 \%\end{array}$ & $\begin{array}{l}2015 \\
\text { (FDA) }\end{array}$ \\
\hline & $\mathrm{RCC}$ & NCT01136733 [68] & $\begin{array}{l}\text { Phase II, lenvatinib + everolimus vs. } \\
\text { lenvatinib vs. everolimus }\end{array}$ & $\begin{array}{l}\mathrm{HR}=0.4 \\
p=0.0005^{*}\end{array}$ & $\begin{array}{l}\mathrm{HR}=0.51 \\
p=0.024^{*}\end{array}$ & $\begin{array}{l}43 \% \text { vs. } \\
27 \% \text { vs. } 6 \%\end{array}$ & $\begin{array}{l}2016 \\
\text { (FDA) }\end{array}$ \\
\hline & $\mathrm{HCC}$ & NCT01761266 [69] & Phase III, lenvatinib vs. sorafenib & $\begin{array}{l}H R=0.64 \\
p<0.0001\end{array}$ & $H R=0.92$ & $\begin{array}{l}40.6 \% \text { vs. } \\
12.4 \%\end{array}$ & $\begin{array}{l}2018 \\
\text { (FDA) }\end{array}$ \\
\hline $\begin{array}{l}\text { Apatinib } \\
\text { (Hengrui) }\end{array}$ & GC & NCT01512745 [73] & Phase III, apatinib vs. placebo & $\begin{array}{l}\mathrm{HR}=0.709 \\
p=0.015\end{array}$ & $\begin{array}{l}\mathrm{HR}=0.444 \\
p<0.001\end{array}$ & $2.8 \%$ vs. $0 \%$ & $\begin{array}{l}2014 \\
\text { (CFDA) }\end{array}$ \\
\hline $\begin{array}{l}\text { Anlotinib (Chia- } \\
\text { taiTianqing) }\end{array}$ & $\mathrm{NSCLC}$ & NCT02388919 [76] & Phase III, anlotinib vs. placebo & $\begin{array}{l}H R=0.25 \\
p<0.001\end{array}$ & $\begin{array}{l}H R=0.68 \\
p=0.002\end{array}$ & $\begin{array}{l}9.2 \% \text { vs. } \\
0.7 \%\end{array}$ & $\begin{array}{l}2018 \\
\text { (CFDA) }\end{array}$ \\
\hline $\begin{array}{l}\text { Fruquintinib } \\
\text { (Hutchison) }\end{array}$ & CRC & NCT02314819 [80] & Phase III, fruquintinib vs. placebo & $\begin{array}{l}H R=0.26 \\
p<0.001\end{array}$ & $\begin{array}{l}\mathrm{HR}=0.65 \\
p<0.001\end{array}$ & $4.7 \%$ vs. $0 \%$ & $\begin{array}{l}2018 \\
\text { (CFDA) }\end{array}$ \\
\hline
\end{tabular}

Abbreviation: RCC renal cell carcinoma, HCC hepatocellular carcinoma, DTC differentiated thyroid cancer, GIST gastro-intestinal stromal tumor, pNETS pancreatic neuroendocrine tumors, STS soft tissue sarcoma, CRC colorectal cancer, MTC medullary thyroid cancer, IPF idiopathic pulmonary fibrosis, NSCLC non-small cell lung cancer, GC gastric cancer, PFS progression-free survival, OS overall survival, ORR objective response rate, NA not available, FDA US Food and Drug Administration, CFDA China Food and Drug Administration, EMA European Medicines Agency 
improved the PFS and ORR rate compared with placebo; thereby, pazopanib was approved by the FDA in 2009 for advanced RCC patients. As both pazopanib and sunitinib have shown benefit in patients with RCC as first-line treatment, the efficacy and safely comparison between them were worth of consideration. The COMPARZ study was the first head-to-head phase III trial comparing sunitinib vs. pazopanib as first-line treatment for advanced RCC patients [38]. This study showed PFS was not inferior in the pazopanib group compared to the sunitinib group, and the ORR was higher in the pazopanib group $(p<0.05)$ and the OS between these two groups showed no statistical significance. Guo et al. further analyzed the safety of pazopanib and sunitinib in Asian and non-Asian subpopulations, indicating well-tolerated in both subpopulations [39]. In addition to the COMPARZ trial, the PISCES study adopted patients' preference as the primary end point, and the result demonstrated patients favored pazopanib over sunitinib on account of the toxicity profile and health-related quality of life (HRQoL) score [40]. Noticeably, tolerability profiles were different between two drugs despite they shared the similar target pathways that is pazopanib has a lower incidence of $3 / 4$ grade fatigue, hand-foot syndrome, and myelosuppression but more frequent hepatic injury [41]. Such discrepancy in toxicities should be considered for patients with specific conditions. Additionally, based on the results of PALETTE trial, pazopanib was approved by the FDA as a treatment for advanced soft tissue sarcoma (STS) in April 2012 [42]. As many as 369 metastatic non-adipocytic STS patients who failed after the standard chemotherapy were randomly assigned to receive pazopanib or placebo in a 2:1 ratio. Both the median PFS and OS were longer in the pazopanib group compared with placebo arm (PFS 4.6 vs. 1.6 months, $p<0.0001$; OS 12.5 vs. 10.7 months, $p=$ $0.2514)$. The response rate was $0 \%$ in the placebo group and $9 \%$ in the pazopanib group [42].

\section{Axitinib}

Axitinib, targeting VEGFR-1/2/3, PDGFR- $\alpha / \beta$, and c-Kit receptor, was approved by the FDA in 2012 for the second-line treatment of patients with advanced RCC [41]. The phase III AXIS study indicated that the median PFS was longer in the axitinib group compared to the sorafenib group (6.7 vs. 4.7 months, $p<0.0001)$ and the ORR was also higher in the axitinib arm [43]. According to the update results of the AXIS trial, no difference of OS was found between these two arms [44]. The most commonly treatment-related side effects were diarrhea, hypertension, and fatigue, and the incidence of hypertension appears higher in axitinib than other TKIs [45].

\section{Regorafenib}

Regorafenib could inhibit a number of key angiogenic RTKs, including VEGFR-1/2/3, PDGFR- $\alpha / \beta$, FGFR-1/2, Tie2, and c-Kit receptor [46]. It had demonstrated clinical effectiveness in patients with metastatic colorectal cancer (mCRC) who had progress after prior standard therapy and approved by the FDA in 2012. Two large randomized phase III trials, CORRECT and CONCUR, demonstrated that regorafenib prolonged the median OS and PFS in mCRC patients, and the drug-related adverse events were manageable $[47,48]$. Based on the results of phase III GRID clinical trial [49], the FDA expanded the indication of regorafenib to patients with advanced GIST following the failure of imatinib and sunitinib in 2013. In this study, regorafenib improved the PFS to 4.8 months and the placebo arm was just 0.9 months, but no difference in the OS were observed between these two groups ( $\mathrm{HR}=0.77, p=0.199)$. The most common regorafenib-related AEs of grade 3 or higher were hypertension (23\%), hand-foot skin reaction (20\%), and diarrhea (5\%) [49]. Recently, a large phase III clinical trial (RESORCE) laid the foundation of the approved of regorafenib in HCC [50]. In RESORCE trial, 573 patients who failed or tolerated sorafenib were enrolled, and the results demonstrated that regorafenib significantly prolonged OS (10.6 vs. 7.8 months, $p<0.0001)$ and PFS (3.1 vs. 1.5 months, $p<0.0001)$. The most common AEs were hand-foot skin reaction, diarrhea, and fatigue. Based on the result of RESORCE trial, the FDA approved the regorafenib for the second line HCC [51].

\section{Cabozantinib}

Cabozantinib is a small pan-tyrosine kinase inhibitor for VEGFR-1/2/3, c-Kit receptor, c-Met, and FLT-3 [52]. The approval of cabozantinib by the FDA in November 2012 for metastatic medullary thyroid cancer (MTC) was based on a phase III trial (EXAM) [53]. In this study, 330 patients with progressive metastatic MTC were randomly assigned to cabozantinib arm or placebo arm. The study reached its primary end point by indicating an improvement of PFS in cabozantinib arm (11.2 vs. 4.0 months, $p<0.001)$. The ORR was $28 \%$ with cabozantinib compared to $0 \%$ with placebo, while no statistically significant difference in OS was observed between these two arms. The most common AEs were diarrhea and palmar-plantar erthyrodysesthesia syndrome [54]. Cabozantinib also demonstrated its antitumor efficacy compared with everolimus in $\mathrm{mRCC}$ who had progressed after VEGFR-targeted therapy. The pivotal phase III METEOR trial had leaded the approval by the FDA for advanced $\mathrm{mRCC}$ as second-line treatment $[55,56]$. According to the result, the median PFS was 7.4 months in the cabozantinib group and 3.8 months in the everolimus group, and ORR was increased by $16 \%$ in 
cabozantinib group $(21 \%$ vs. $5 \%, p<0.001)$ [55]. More importantly, the final updated results show a significant improvement in OS with cabozantinib (21.4 months vs. 16.5 months, $p=0.0003$ ) [56]. More importantly, cabozantinib was expected to become a novel systemic therapy for patients with metastatic hepatocellular carcinoma (mHCC) based on the positive result of CELESTIAL trial [57]. The study showed that treatment with cabozantinib resulted in longer OS (10.2 vs. 8.0 months, $p=0.005)$ and PFS (5.2 vs. 1.9 months, $p<0.001)$, and the ORR was also higher in cabozantinib arm ( $4 \%$ vs. $1 \%, p=0.009)$ [57]. Encouragingly, cabozantinib garnered FDA approval for mHCC patients after the failure of sorafenib in January 2019.

\section{Nintedanib}

Nintedanib is a multiple angio-kinase inhibitor targeting VEGFR-1/2/3, PDGFR- $\alpha / \beta$, and FGFR-1/2 [58]. It has initially approved by the FDA for the treatment of idiopathic pulmonary fibrosis (IPF) [59] depending on the TOMORROW trial [60] and INPULSIS-1/2 trial [61]. In the same year, nintedanib combined with docetaxel therapy was approved for non-squamous non-small cell lung cancer (NSCLC) patients as a second-line treatment by the European Medicines Agency (EMA) but not by the FDA [62]. In a pivotal randomized, double-blind phase III trial (LUME-Lung 1), PFS was improved in the docetaxel plus nintedanib group in relative to placebo plus docetaxel (3.4 vs. 2.7 months, $p=0.0019$ ) [63], while the OS showed no discrepancy (10.1 months vs. 9.1 months, $p=0.2720$ ). Interestingly, analysis in patients with adenocarcinoma histology showed a prolonged PFS (HR $=0.77, p=0.0193)$ and OS $(\mathrm{HR}=0.83, p=0.0359)$ in the docetaxel plus nintedanib group. AEs were more common in the docetaxel plus nintedanib group compared with the docetaxel plus placebo group with diarrhea, decreased neutrophils, and fatigue. Subsequently, Hanna et al. conducted a phase III trial, LUME-Lung 2 study, comparing the efficacy of nintedanib plus pemetrexed in patients with NSCLC exclusively [64]. Although the clinical trial was stopped prematurely, a PFS advantage was observed in the nintedanib plus pemetrexed group in the subsequent analysis. However, the subgroup analysis in adenocarcinoma histology showed no discrepancy between two arms, which was inconsistent with the findings in LUME-Lung 1 study. The real value of nintedanib in the second-line therapy of advanced NSCLC remained unclear.

\section{Lenvatinib}

Lenvatinib is a kinase inhibitor targeting VEGFR-1/2/3, PDGFR- $\alpha / \beta$, FGFR-1/2/3, Ret, and c-Kit [65]. It was first approved for patients with advanced RAI refractory DTC by the FDA based on the results of the SELECT study [66, 67]. In this study, lenvatinib significantly prolonged the PFS (18.3 vs. 3.6 months, $p<0.001)$ and improved the ORR $(64.8 \%$ vs. $1.5 \%, p=0.001)$. The most frequent side effects were hypertension, diarrhea, and fatigue/asthenia. Considering the dramatic efficacy and manageable side effects, the FDA expedited the approval of lenvatinib for RAI-refractory DTCs [65]. Encouragingly, it also showed anti-neoplastic activity in other solid tumors, including advanced RCC and HCC. Lenvatinib gained the FDA approval for the treatment of metastatic RCC based on the positive result of a phase II clinical trial [68]. The study was designed to assess whether the combination of lenvatinib plus everolimus was superior compared to the single agents. The primary end point of PFS in the combination group was significantly longer than everolimus alone (14.6 vs. 5.5 months, $p=0.0005)$. The ORR in lenvatinib plus everolimus arm, lenvatinib alone arm, and everolimus alone arm were $43 \%, 27 \%$, and $6 \%$, respectively. Additionally, the incidence of grade $3-4$ AEs was $71 \%$ in patients receiving lenvatinib plus everolimus, $79 \%$ in single-agent lenvatinib, and 50\% in single-agent everolimus [68]. Based on these results, lenvatinib in combination with everolimus was recommended as a second-line systemic therapy in mRCC. Lenvatinib garnered the FDA approval for HCC in 2018 based on a series of clinical trials, among which a global phase III trial (REFLECT) was the most important [69]. This study aimed to assess the efficacy of lenvatinib vs. sorafenib as a first-line treatment for patients with unresectable HCC. The result was notable that the OS in lenvatinib group was non-inferior to the sorafenib group (13.6 vs. 12.3 months), and the PFS of lenvatinib group was longer than that of sorafenib (7.4 vs. 3.7 months, $p<0.0001$ ) [69]. Lenvatinib also showed a greater ORR compared with the sorafenib group (24.1\% vs. $9.2 \%, p<0.0001)$, and the treatment-emergent AEs were tolerable in both groups $[69,70]$. Lenvatinib, as the second first-line agent for advanced HCC patients, was a great breakthrough in the field of $\mathrm{HCC}$ in the past 10 years.

\section{Apatinib}

The past decade has also witnessed the great progress in the development of anti-tumor drugs developed by Chinese researchers. Apatinib can simultaneously suppress the kinase activities of VEGFR-2, c-Kit, and c-Src and is approved by the CFDA for the treatment of advanced gastric cancer (GC) in October 2014 [71, 72]. The efficacy and safety profile of apatinib in patients with metastatic gastric or gastroesophageal junction adenocarcinoma who had failed at least two lines of chemotherapy was evaluated in a series of clinical trials. A phase III randomized clinical trial, conducted by $\mathrm{Li}$ and collaborators, has indicated its important role in 
three or more lines for GC patients [73]. The primary end points of OS and PFS were significantly prolonged by apatinib (OS 6.5 vs. 4.7 months; PFS 2.6 vs. 1.8 months). Though the ORR showed no difference between two groups, the disease control rate (DCR) favored apatinib over placebo treatment. The major treatment-related grade 3-4 AEs in apatinib arm included hand-foot syndrome, proteinuria, and hypertension [73].

\section{Anlotinib}

Anlotinib targets VEGFR-1/2/3, FGFR-1-4, PDGFR- $\alpha / \beta$, c-Kit, and Ret [74]. The ALTER0302 trial demonstrated 3.6 months longer PFS in NSCLC patients receiving anlotinib [75]. Soon after, the ALTER0303 trial was conducted, further confirming the drug's efficacy in advanced NSCLC [76]. The results showed that both OS (9.6 vs. 6.3 months, $p=0.002)$ and PFS (5.4 vs. 1.4 months, $p<0.001$ ) were significantly longer in the anlotinib group compared with placebo. Anlotinib also produced significant ORR and DCR benefits vs. placebo and had a manageable safety profile [76, 77]. It was approved by the CFDA as a third-line or further therapy for advanced NSCLC patients in 2018. Until now, apatinib and anlotinib have not gained the approval of the FDA, but both of them were identified as orphan drugs in the USA.

\section{Fruquintinib}

Fruquintinib is a potent small molecule inhibitor of VEGFR-1/2/3 [78]. In the phase II clinical trials, fruquintinib showed a significant PFS benefit in patients with treatment-refractory mCRC [79]. Then, a randomized, double bind, phase III (FRESCO) trial conducted by Li et al. laid the foundation for the approval of this drug on patients with mCRC by the CFDA in 2018 [80]. In this study, $\mathrm{mCRC}$ patients who had progressed after at least two lines of chemotherapy were allocated to receive either fruquintinib or placebo. The primary end point median of OS was significantly longer in the fruquintinib group compared to placebo (9.3 vs. 6.6 months, $p<0.001)$, and the median PFS also significantly increased by fruquintinib (3.7 vs. 1.8 months, $p<0.001$ ). Moreover, higher ORR and DCR were observed in patients receiving fruquintinib with a manageable safety profile. Additionally, a phase I clinical trial is ongoing in the USA, exploring the efficacy and safety in non-Chinese populations [81].

\section{Novel anti-angiogenic TKIs under investigation}

While the approved anti-angiogenic TKIs are trying to expand their indication in other cancer types, numerous new anti-angiogenic TKIs are also being extensively explored. Three representative TKI drugs with potential to be approved in the near future are presented.
Motesanib, also named AMG 706, is an orally multi-targeted inhibitor of VEGFR-1/2/3, PDGFR- $\alpha / \beta$, and $\mathrm{c}-\mathrm{Kit}$ [82]. Motesanib was considered as a potent anti-tumor drug in Asian advanced NSCLC patients based on the subgroup analysis of MONET1 trial [83]. However, the results of later phase III trial (MONETA) were disappointing with no advantage in patients receiving motesanib plus paclitaxel and carboplatin over placebo plus paclitaxel and carboplatin [84]. Nevertheless, two phase II trials have indicated remarkable anticancer activity of motesanib among patients with advanced thyroid cancer $[85,86]$. Recently, Lubner et al. examined the efficacy of motesanib in low-grade NETs in a phase II trial [87]. The study reached its primary objective with a 4-month PFS of $78.5 \%$, and the median PFS in all patients was 8.7 months. All in all, motesanib is as potential as a systemic targeted therapy for NETs, but its niche in the treatment of NETs still needs further study.

Cediranib, also named AZD-2171, is a potent inhibitor of VEGF signaling that binds all three VEGFR (VEGFR-1/2/3), together with c-Kit and PDGFR- $\alpha / \beta$ [88]. Though, cediranib had failed phase III clinical trials in NSCLC [89], mCRC [90, 91], and recurrent glioblastoma [92], it showed new hope in recurrent ovarian cancer. The ICON6 trial evaluated the efficacy and safety of cediranib plus platinum-based chemotherapy and as continued maintenance treatment in patients with relapsed platinum-sensitive ovarian cancer [93]. Unfortunately, the ICON6 trail was prematurely terminated on account of the depressing results in other cancer types. Finally, a total of 486 women were randomly allocated to arm A (chemotherapy plus placebo 6 cycles and continued placebo), arm B (chemotherapy plus cediranib 6 cycles and switched to placebo), and arm $\mathrm{C}$ (chemotherapy plus cediranib 6 cycles and continued cediranib). The median PFS was significantly longer in arm $\mathrm{C}$ at 11 months, compared to 8.7 months in arm A $(p<$ 0.0001) [93], and the OS was 7.4 months higher in arm C compared to arm A $(p=0.21)$ [94]. Most common side effects of grade 3-4 in arm $C$ were neutropenia, fatigue, and hypertension during the chemotherapy phase and diarrhea, fatigue, and neutropenia during maintenance treatment.

Sulfatinib is a multi-target TKI targeting VEGFR-1/2/ 3, FGFR1, and colony stimulating factor 1 receptor (CSF1R). A phase I study (NCT02133157) observed an acceptable safety profile and encouraging antitumor activity in patients with advanced solid tumors, particularly in NETs [95]. At present, one phase II study (NCT02267967) and two phase III studies (NCT02589821, NCT02588170) conducted on advanced NETs are ongoing [96]. 


\section{Anti-angiogenic receptor TKIs in combination with immunotherapy}

Immunotherapy has been changing the paradigm of oncology treatment in the recent years [97-99]. Whether the combination of TKIs and immunotherapy can create synthetic effect is a hot topic. The emerging evidences suggest that anti-angiogenic therapy may not only inhibit neo-vascular formation, but also regulate the immune microenvironment [100]. This provided a theoretic basis for the combination of TKIs and immunotherapy. Subsequently, hundreds of clinical trials were designed to access the efficacy of combining TKIs with immune checkpoint blockade. A phase Ib study (JAVELIN Renal 100) conducted by Choueiri et al. interrogated the combination therapy of axitinib plus avelumab (a PD-L1 mAb) in advanced RCC patients [101]. The DCR reached $78 \%$ in 55 patients with three complete responses and the safety profile was manageable. These encouraging results supported the further study of these drug combinations. Now, the phase III JAVELIN Renal 101 trial finished [102]. The result showed that in 866 patients with mRCC, the axitinib plus avelumab group showed a remarkable improvement in median PFS compared with sunitinib (13.8 vs. 8.4 months, $p<0.0001$ ), and the ORR were $51.4 \%$ and $25.7 \%$, respectively. Furthermore, among patients with PD-L1+ tumors, the ORR and the PFS also favored the combination group [102]. The combination of axitinib and avelumab would be a promising strategy for patients with mHCC based on the positive result of JAVELIN Renal 101. Other combinations such as lenvatinib plus pembrolizumab or SHR 1210 plus apatinib in patients with HCC were also ongoing [103]. The combination of immunotherapy with TKIs has demonstrated promising outcome in a certain type of carcinomas, but further optimized combinations are required and caution must be taken to avoid severe toxicity.

\section{Future perspectives}

The development of anti-angiogenic agents has attracted great attention. Bevacizumab, the first clinically approved anti-VEGF targeted agents, provides a first proof of principle of anti-angiogenic treatment in cancer. Though monotherapy with bevacizumab is largely inefficient, it really exerts therapeutic efficacy in various types of carcinoma when in combination with chemotherapy [104]. Because tumor angiogenesis is regulated by multiple pathways, many interconnected pathways can compensate the effect of single inhibition of VEGF signaling. It seems that multi-targeted TKIs hold a therapeutic advantage over monoclonal antibody as they can block multiple angiogenic signaling pathways simultaneously. Indeed, TKIs have shown their efficacy in many types of cancers, mainly RCC and HCC. Although all anti-angiogenic receptor TKIs share the same mechanism of action and the similar spectrum of targeted kinases, they are different in their pharmacokinetics and substance-specific AEs. The one possible explanation may be that the subtle difference on chemical structure leads to the variable affinity and potency to targets. Another possibility is that those TKIs may act on some unidentified targets beyond known kinases. With more and more anti-cancer agents available, it is a challenge for the oncologist to make an optimal choice in the sequence of treatment. For instance, 12 drugs have been approved for patients with HCC, including 6 anti-angiogenic TKIs until 2017 [105]. Though, the international guidelines have reached a global consensus for the choice of drugs in different lines. The optimal strategy and the sequence of drugs as well as the right time of the incorporation of other therapeutic methods such as surgery, radiology has not yet been resolved. Tolerance of receptor TKIs should also be taken into account.

Another challenge for anti-angiogenesis TKIs is the lack of robust biomarkers to identify patients with cancer who will benefit from anti-angiogenic therapy. Unlike RTK inhibitor, larotrectinib is special for cancer with tropomyosin receptor kinases (TRK) fusion-positive and has demonstrated significant efficiency in patients with different tumor histology [106]. One of the main problems in identifying such a biomarker for anti-angiogenic therapy may come from the complex feedback loops and cross talk between signaling pathways. Currently, some biomarkers have been proposed, such as VEGF, VEGFR-2, FGF-2, or IL-8, but none of them have yet been validated for routine clinical use [104]. Recently, a cohort study conducted by Liu et al. indicated a positive correlation between the anti-angiogenesis-related AEs and prolonged OS [107]. It means that side effects, such as high blood pressure, hypothyroidism, or hand-foot syndrome, may associate with the anti-tumor efficacy. Similarly, Rini et al. demonstrated that patients with diastolic blood pressure $\geq 90$ $\mathrm{mmHg}$ had a longer OS and PFS [108]. As there are no molecular biomarkers available for clinical use, those side effects might be helpful for clinical decision.

The future of TKIs could be their positioning besides metastatic setting, such as in adjuvant therapy and neoadjuvant treatment. There were three well-known phase III clinical trials that explored the use of TKIs in RCC in adjuvant setting, namely ASSURE (adjuvant sunitinib vs. sorafenib vs. placebo), PROTECT (pazopanib vs. placebo), and S-TRAC (sunitinib vs. placebo) [109-111]. Only S-TRAC study showed a significant improvement by sunitinib in disease-free survival in high-risk RCC after nephrectomy [111]. Based on the result of S-TRAC trial, sunitinib was approved by the FDA as an adjuvant 
therapy for RCC patents in 2017. Unfortunately, adjuvant sorafenib for HCC patients reached a negative result [112]. The utilization of TKIs before surgery has also been studied. A phase II trial explored the safety and efficacy of the use of pazopanib prior to cytoreductive nephrectomy RCC patients, suggesting the safety, and clinical benefit could be expected [113]. The precision role of anti-angiogenic TKI in adjuvant and neoadjuvant therapy needs further investigation.

It is noted that the indication of these receptor TKIs are mainly restricted to highly vascular tumor, like RCC, HCC, NSCLC, and CRC. Their efficacy in other types of cancers needs further exploration [30]. In most case, anti-angiogenesis treatment increases the PFS of patients, while the increase in OS is unsatisfactory. Great breakthrough in immunotherapy brings new possibility for the combination of TKIs, and positive results in a certain type of carcinoma attract broad attention [114].

\begin{abstract}
Abbreviations
AEs: Adverse events; ANGPT: Angiopoietin; ATP: Adenosine triphosphate; CFDA: China Food and Drug Administration; DCR: Disease control rate; DTC: Differentiated thyroid cancer; EGF: Epidermal growth factor; FDA: US Food and Drug Administration; FGF: Fibroblast growth factor; GC: Gastric cancer; GIST: Gastro-intestinal stromal tumor; mCRC: Metastatic colorectal cancer; MTC: Metastatic medullary thyroid cancer; NETs: Neuroendocrine tumors; NSCLC: Non-small cell lung cancer; ORR: Objective response rate; OS: Overall survival; PDGF: Platelet-derived growth factor; PFS: Progressionfree survival; PIGF: Placenta growth factor; PKIs: Protein kinase inhibitors; RAl: Radioactive iodine; RCC: Renal cell carcinoma; RTKs: Receptor tyrosine kinases; TKIs: Tyrosine kinase inhibitors; VEGF: Vascular endothelial growth factor
\end{abstract}

\section{Acknowledgements}

Not applicable.

\section{Funding}

This work was funded by the National Natural Science Foundation of China (No. 81572608, 81874120). Wuhan Science and Technology Bureau (No. 2017060201010170)

\section{Availability of data and materials}

Data sharing not applicable to this article as no datasets were generated or analyzed during the current study.

\section{Authors' contributions}

SQ and AL performed the selection of literature, drafted the manuscript, and prepared the figures. MY and SY collected the related references. MZ participated in the design and discussion. KW carried out the design of this review and revised the manuscript. All authors contributed to this manuscript. All authors read and approved the final manuscript.

\section{Ethics approval and consent to participate}

Not applicable.

\section{Consent for publication}

Not applicable.

\section{Competing interests}

The authors declare that they have no competing interests.

\section{Publisher's Note}

Springer Nature remains neutral with regard to jurisdictional claims in published maps and institutional affiliations.
Received: 21 January 2019 Accepted: 5 March 2019

Published online: 12 March 2019

\section{References}

1. Hanahan D, Weinberg RA. Hallmarks of cancer: the next generation. Cell. 2011;144:646-74.

2. Gimbrone MA Jr, Leapman SB, Cotran RS, Folkman J. Tumor dormancy in vivo by prevention of neovascularization. J Exp Med. 1972;136:261-76.

3. Folkman J. Angiogenesis in cancer, vascular, rheumatoid and other disease. Nat Med. 1995;1:27-31.

4. Ribatti D, Nico B, Crivellato E, Roccaro AM, Vacca A. The history of the angiogenic switch concept. Leukemia. 2007;21:44-52.

5. Ferrara N, Gerber HP, LeCouter J. The biology of VEGF and its receptors. Nat Med. 2003;9:669-76

6. Fagiani E, Christofori G. Angiopoietins in angiogenesis. Cancer Lett. 2013; 328:18-26.

7. Zheng $X$, Liu Q, Yi M, Qin S, Wu K. The regulation of cytokine signaling by retinal determination gene network pathway in cancer. Onco Targets Ther. 2018:11:6479-87.

8. Seki T, Hosaka K, Lim S, Fischer C, Honek J, Yang Y, et al. Endothelial PDGF$\mathrm{CC}$ regulates angiogenesis-dependent thermogenesis in beige fat. Nat Commun. 2016:7:12152.

9. Folkman J. Antiangiogenesis in cancer therapy--endostatin and its mechanisms of action. Exp Cell Res. 2006;312:594-607.

10. O'Reilly MS, Holmgren L, Shing Y, Chen C, Rosenthal RA, Moses M, et al. Angiostatin: a novel angiogenesis inhibitor that mediates the suppression of metastases by a Lewis lung carcinoma. Cell. 1994;79:315-28.

11. Ferrara N, Hillan KJ, Gerber HP, Novotny W. Discovery and development of bevacizumab, an anti-VEGF antibody for treating cancer. Nat Rev Drug Discov. 2004;3:391-400.

12. Poole RM, Vaidya A. Ramucirumab: first global approval. Drugs. 2014;74: 1047-58.

13. Zhao Y, Adjei AA. Targeting angiogenesis in cancer therapy: moving beyond vascular endothelial growth factor. Oncologist. 2015;20:660-73.

14. Berndt N, Karim RM, Schonbrunn E. Advances of small molecule targeting of kinases. Curr Opin Chem Biol. 2017;39:126-32.

15. Manning G, Whyte DB, Martinez R, Hunter T, Sudarsanam S. The protein kinase complement of the human genome. Science (New York, NY). 2002; 298:1912-34.

16. Ling Y, Xie Q, Zhang Z, Zhang H. Protein kinase inhibitors for acute leukemia. Biomark Res. 2018:6:8.

17. Gotink KJ, Verheul HM. Anti-angiogenic tyrosine kinase inhibitors: what is their mechanism of action? Angiogenesis. 2010;13:1-14.

18. Liu Q, Yu S, Zhao W, Qin S, Chu Q, Wu K. EGFR-TKIs resistance via EGFRindependent signaling pathways. Mol Cancer. 2018;17:53.

19. Cowan-Jacob SW. Structural biology of protein tyrosine kinases. Cell Mol Life Sci. 2006;63:2608-25.

20. Schlessinger J. Cell signaling by receptor tyrosine kinases. Cell. 2000;103: $211-25$.

21. Hubbard SR. Structural analysis of receptor tyrosine kinases. Prog Biophys Mol Biol. 1999; $71: 343-58$

22. Kerbel RS. Tumor angiogenesis. N Engl J Med. 2008;358:2039-49.

23. Hicklin DJ, Ellis LM. Role of the vascular endothelial growth factor pathway in tumor growth and angiogenesis. J Clin Oncol. 2005;23:1011-27.

24. Andrae J, Gallini R, Betsholtz C. Role of platelet-derived growth factors in physiology and medicine. Genes Dev. 2008:22:1276-312.

25. Beenken A, Mohammadi M. The FGF family: biology, pathophysiology and therapy. Nat Rev Drug Discov. 2009;8:235-53.

26. Skouras VS, Maragkos C, Grapsa D, Syrigos KN. Targeting neovasculature with multitargeted antiangiogenesis tyrosine kinase inhibitors in non-small cell lung cancer. BioDrugs. 2016;30:421-39.

27. Escudier B, Eisen T, Stadler WM, Szczylik C, Oudard S, Siebels M, et al. Sorafenib in advanced clear-cell renal-cell carcinoma. N Engl J Med. 2007; 356:125-34

28. Llovet JM, Ricci S, Mazzaferro V, Hilgard P, Gane E, Blanc JF, et al. Sorafenib in advanced hepatocellular carcinoma. N Engl J Med. 2008;359:378-90.

29. Brose MS, Nutting CM, Jarzab B, Elisei R, Siena S, Bastholt L, et al. Sorafenib in radioactive iodine-refractory, locally advanced or metastatic differentiated thyroid cancer: a randomised, double-blind, phase 3 trial. Lancet. 2014;384: $319-28$. 
30. Poddubskaya EV, Baranova MP, Allina DO, Smirnov PY, Albert EA, Kirilchev $A P$, et al. Personalized prescription of tyrosine kinase inhibitors in unresectable metastatic cholangiocarcinoma. Exp Hematol Oncol. 2018;7:21.

31. Motzer RJ, Escudier B, Gannon A, Figlin RA. Sunitinib: ten years of successful clinical use and study in advanced renal cell carcinoma. Oncologist. 2017;22: 41-52.

32. Demetri GD, van Oosterom AT, Garrett CR, Blackstein ME, Shah MH, Verweij $J$, et al. Efficacy and safety of sunitinib in patients with advanced gastrointestinal stromal tumour after failure of imatinib: a randomised controlled trial. Lancet. 2006;368:1329-38.

33. Motzer RJ, Hutson TE, Tomczak P, Michaelson MD, Bukowski RM, Rixe O, et al. Sunitinib versus interferon alfa in metastatic renal-cell carcinoma. N Engl J Med. 2007;356:115-24.

34. Motzer RJ, Hutson TE, Tomczak P, Michaelson MD, Bukowski RM, Oudard S, et al. Overall survival and updated results for sunitinib compared with interferon alfa in patients with metastatic renal cell carcinoma. J Clin Oncol. 2009:27:3584-90.

35. Raymond E, Dahan L, Raoul JL, Bang YJ, Borbath I, Lombard-Bohas C, et al. Sunitinib malate for the treatment of pancreatic neuroendocrine tumors. N Engl J Med. 2011;364:501-13.

36. Frampton JE. Pazopanib: a review in advanced renal cell carcinoma. Target Oncol. 2017;12:543-54

37. Sternberg CN, Davis ID, Mardiak J, Szczylik C, Lee E, Wagstaff J, et al. Pazopanib in locally advanced or metastatic renal cell carcinoma: results of a randomized phase III trial. J Clin Oncol. 2010;28:1061-8.

38. Motzer RJ, Hutson TE, Cella D, Reeves J, Hawkins R, Guo J, et al. Pazopanib versus sunitinib in metastatic renal-cell carcinoma. N Engl J Med. 2013;369: 722-31.

39. Guo J, Jin J, Oya M, Uemura H, Takahashi S, Tatsugami K, et al. Safety of pazopanib and sunitinib in treatment-naive patients with metastatic renal cell carcinoma: Asian versus non-Asian subgroup analysis of the COMPARZ trial. J Hematol Oncol. 2018;11:69.

40. Escudier B, Porta C, Bono P, Powles T, Eisen T, Sternberg CN, et al. Randomized, controlled, double-blind, cross-over trial assessing treatment preference for pazopanib versus sunitinib in patients with metastatic renal cell carcinoma: PISCES study. J Clin Oncol. 2014;32:1412-8.

41. Zarrabi K, Fang C, Wu S. New treatment options for metastatic renal cell carcinoma with prior anti-angiogenesis therapy. J Hematol Oncol. 2017;10: 38.

42. van der Graaf WT, Blay JY, Chawla SP, Kim DW, Bui-Nguyen B, Casali PG, et al. Pazopanib for metastatic soft-tissue sarcoma (PALETTE): a randomised, double-blind, placebo-controlled phase 3 trial. Lancet. 2012;379:1879-86.

43. Rini BI, Escudier B, Tomczak P, Kaprin A, Szczylik C, Hutson TE, et al. Comparative effectiveness of axitinib versus sorafenib in advanced renal cell carcinoma (AXIS): a randomised phase 3 trial. Lancet. 2011:378:1931-9.

44. Motzer RJ, Escudier B, Tomczak P, Hutson TE, Michaelson MD, Negrier S, et al. Axitinib versus sorafenib as second-line treatment for advanced renal cell carcinoma: overall survival analysis and updated results from a randomised phase 3 trial. Lancet Oncol. 2013;14:552-62.

45. Keating GM. Axitinib: a review in advanced renal cell carcinoma. Drugs. 2015;75:1903-13.

46. de la Fouchardiere C. Regorafenib in the treatment of metastatic colorectal cancer. Future Oncol. 2018;14:2239-46.

47. Grothey A, Van Cutsem E, Sobrero A, Siena S, Falcone A, Ychou M, et al. Regorafenib monotherapy for previously treated metastatic colorectal cancer (CORRECT): an international, multicentre, randomised, placebocontrolled, phase 3 trial. Lancet. 2013;381:303-12.

48. Li J, Qin S, Xu R, Yau TC, Ma B, Pan H, et al. Regorafenib plus best supportive care versus placebo plus best supportive care in Asian patients with previously treated metastatic colorectal cancer (CONCUR): a randomised, double-blind, placebo-controlled, phase 3 trial. Lancet Oncol. 2015;16:619-29

49. Demetri GD, Reichardt P, Kang YK, Blay JY, Rutkowski P, Gelderblom H, et al. Efficacy and safety of regorafenib for advanced gastrointestinal stromal tumours after failure of imatinib and sunitinib (GRID): an international, multicentre, randomised, placebo-controlled, phase 3 trial. Lancet. 2013;381: 295-302.

50. Bruix J, Qin S, Merle P, Granito A, Huang YH, Bodoky G, et al. Regorafenib for patients with hepatocellular carcinoma who progressed on sorafenib treatment (RESORCE): a randomised, double-blind, placebo-controlled, phase 3 trial. Lancet. 2017;389:56-66.
51. Medavaram S, Zhang Y. Emerging therapies in advanced hepatocellular carcinoma. Exp Hematol Onco. 2018;7:17.

52. Ranieri G, Marech I, Asabella AN, Di Palo A, Porcelli M, Lavelli V, et al. Tyrosine-kinase inhibitors therapies with mainly anti-angiogenic activity in advanced renal cell carcinoma: value of PET/CT in response evaluation. Int J Mol Sci. 2017;18(9). https://doi.org/10.3390/ijms18091937.

53. Elisei R, Schlumberger MJ, Muller SP, Schoffski P, Brose MS, Shah MH, et al. Cabozantinib in progressive medullary thyroid cancer. J Clin Oncol. 2013;31: 3639-46.

54. Priya SR, Dravid CS, Digumarti R, Dandekar M. Targeted therapy for medullary thyroid cancer: A review. Front Oncol. 2017;7:238.

55. Choueiri TK, Escudier B, Powles T, Mainwaring PN, Rini BI, Donskov F, et al. Cabozantinib versus everolimus in advanced renal-cell carcinoma. N Engl J Med. 2015;373:1814-23.

56. Choueiri TK, Escudier B, Powles T, Tannir NM, Mainwaring PN, Rini BI, et al. Cabozantinib versus everolimus in advanced renal cell carcinoma (METEOR): final results from a randomised, open-label, phase 3 trial. Lancet Oncol. 2016;17:917-27.

57. Abou-Alfa GK, Meyer T, Cheng AL, El-Khoueiry AB, Rimassa L, Ryoo BY, et al. Cabozantinib in patients with advanced and progressing hepatocellular carcinoma. N Engl J Med. 2018:379:54-63.

58. Dhillon S. Nintedanib: a review of its use as second-line treatment in adults with advanced non-small cell lung cancer of adenocarcinoma histology. Target Oncol. 2015;10:303-10.

59. Keating GM. Nintedanib: A review of its use in patients with idiopathic pulmonary fibrosis. Drugs. 2015;75:1131-40.

60. Richeldi L, Costabel U, Selman M, Kim DS, Hansell DM, Nicholson AG, et al. Efficacy of a tyrosine kinase inhibitor in idiopathic pulmonary fibrosis. $\mathrm{N}$ Engl J Med. 2011;365:1079-87.

61. Richeldi L, du Bois RM, Raghu G, Azuma A, Brown KK, Costabel U, et al. Efficacy and safety of nintedanib in idiopathic pulmonary fibrosis. N Engl J Med. 2014:370:2071-82.

62. Alshangiti A, Chandhoke G, Ellis PM. Antiangiogenic therapies in non-smallcell lung cancer. Curr Oncol. 2018;25:S45-58.

63. Reck M, Kaiser R, Mellemgaard A, Douillard JY, Orlov S, Krzakowski M, et al. Docetaxel plus nintedanib versus docetaxel plus placebo in patients with previously treated non-small-cell lung cancer (LUME-Lung 1): a phase 3, double-blind, randomised controlled trial. Lancet Oncol. 2014;15:143-55.

64. Hanna NH, Kaiser R, Sullivan RN, Aren OR, Ahn MJ, Tiangco B, et al. Nintedanib plus pemetrexed versus placebo plus pemetrexed in patients with relapsed or refractory, advanced non-small cell lung cancer (LUMELung 2): a randomized, double-blind, phase III trial. Lung Cancer. 2016;102: $65-73$.

65. Yeung KT, Cohen EE. Lenvatinib in advanced, radioactive iodine-refractory, differentiated thyroid carcinoma. Clin Cancer Res. 2015;21:5420-6.

66. Scott LJ. Lenvatinib: first global approval. Drugs. 2015;75:553-60.

67. Schlumberger M, Tahara M, Wirth $L$, Robinson B, Brose MS, Elisei $R$, et al. Lenvatinib versus placebo in radioiodine-refractory thyroid cancer. $N$ Engl J Med. 2015:372:621-30

68. Motzer RJ, Hutson TE, Glen H, Michaelson MD, Molina A, Eisen T, et al. Lenvatinib, everolimus, and the combination in patients with metastatic renal cell carcinoma: a randomised, phase 2, open-label, multicentre trial. Lancet Oncol. 2015;16:1473-82.

69. Kudo M, Finn RS, Qin S, Han KH, Ikeda K, Piscaglia F, et al. Lenvatinib versus sorafenib in first-line treatment of patients with unresectable hepatocellular carcinoma: a randomised phase 3 non-inferiority trial. Lancet. 2018;391: 1163-73.

70. Forner A, Reig M, Bruix J. Hepatocellular carcinoma. Lancet. 2018;391:1301-14.

71. Aoyama T, Yoshikawa T. Targeted therapy: apatinib - new third-line option for refractory gastric or GEJ cancer. Nat Rev Clin Oncol. 2016;13:268-70.

72. Tian S, Quan H, Xie C, Guo H, Lu F, Xu Y, et al. YN968D1 is a novel and selective inhibitor of vascular endothelial growth factor receptor-2 tyrosine kinase with potent activity in vitro and in vivo. Cancer Sci. 2011:102:1374-80

73. Li J, Qin S, Xu J, Xiong J, Wu C, Bai Y, et al. Randomized, double-blind placebo-controlled phase III trial of apatinib in patients with chemotherapyrefractory advanced or metastatic adenocarcinoma of the stomach or gastroesophageal junction. J Clin Oncol. 2016;34:1448-54.

74. Syed YY. Anlotinib: first global approval. Drugs. 2018;78:1057-62.

75. Han BH, Li K, Zhao YZ, Li BL, Cheng Y, Zhou JY, et al. Anlotinib as a thirdline therapy in patients with refractory advanced non-small-cell lung cancer: 
a multicentre, randomised phase II trial (ALTER0302). Br J Cancer. 2018;118: 654-61.

76. Han B, Li K, Wang Q, Zhang L, Shi J, Wang Z, et al. Effect of anlotinib as a thirdline or further treatment on overall survival of patients with advanced nonsmall cell lung cancer: the ALTER 0303 phase 3 randomized clinical trial. JAMA Oncol. 2018:4:1569-75.

77. Shen G, Zheng F, Ren D, Du F, Dong Q, Wang Z, et al. Anlotinib: a novel multi-targeting tyrosine kinase inhibitor in clinical development. J Hematol Oncol. 2018;11:120

78. Su S, Wu YL. Clinical trials of tyrosine kinase inhibitors for lung cancer in China: a review. J Hematol Oncol. 2017;10:147.

79. $X u$ RH, Li J, Bai Y, Xu J, Liu T, Shen L, et al. Safety and efficacy of fruquintinib in patients with previously treated metastatic colorectal cancer: a phase lb study and a randomized double-blind phase II study. J Hematol Oncol. 2017;10:22.

80. Li J, Qin S, Xu RH, Shen L, Xu J, Bai Y, et al. Effect of fruquintinib vs placebo on overall survival in patients with previously treated metastatic colorectal cancer: the FRESCO randomized clinical trial. Jama. 2018;319:2486-96.

81. Shirley M. Fruquintinib: first global approval. Drugs. 2018;78:1757-61.

82. Polverino A, Coxon A, Starnes C, Diaz Z, DeMelfi T, Wang L, et al. AMG 706 an oral, multikinase inhibitor that selectively targets vascular endothelial growth factor, platelet-derived growth factor, and kit receptors, potently inhibits angiogenesis and induces regression in tumor xenografts. Cancer Res. 2006;66:8715-21.

83. Kubota K, Ichinose Y, Scagliotti G, Spigel D, Kim JH, Shinkai T, et al. Phase III study (MONET1) of motesanib plus carboplatin/paclitaxel in patients with advanced nonsquamous nonsmall-cell lung cancer (NSCLC): Asian subgroup analysis. Ann Oncol. 2014;25:529-36.

84. Kubota K, Yoshioka H, Oshita F, Hida T, Yoh K, Hayashi H, et al. Phase III, randomized, placebo-controlled, double-blind trial of motesanib (AMG-706) in combination with paclitaxel and carboplatin in east Asian patients with advanced nonsquamous non-small-cell lung cancer. J Clin Oncol. 2017;35: 3662-70.

85. Schlumberger MJ, Elisei R, Bastholt L, Wirth $L$, Martins RG, Locati LD, et al. Phase II study of safety and efficacy of motesanib in patients with progressive or symptomatic, advanced or metastatic medullary thyroid cancer. J Clin Oncol. 2009;27:3794-801.

86. Sherman SI, Wirth LJ, Droz JP, Hofmann M, Bastholt L, Martins RG, et al. Motesanib diphosphate in progressive differentiated thyroid cancer. N Engl J Med. 2008:359:31-42.

87. Lubner S, Feng Y, Mulcahy M, O'Dwyer P, Giang GY, Hinshaw JL, et al. E4206: AMG 706 and octreotide in patients with low-grade neuroendocrine tumors. Oncologist. 2018;23:1006-e1104.

88. Mahner S, Woelber L, Mueller V, Witzel I, Prieske K, Grimm D, et al. Beyond bevacizumab: an outlook to new anti-angiogenics for the treatment of ovarian cancer. Front Oncol. 2015;5:211.

89. Goss GD, Arnold A, Shepherd FA, Dediu M, Ciuleanu TE, Fenton D, et al. Randomized, double-blind trial of carboplatin and paclitaxel with either daily oral cediranib or placebo in advanced non-small-cell lung cancer: NCIC clinical trials group BR24 study. J Clin Oncol. 2010;28:49-55.

90. Hoff PM, Hochhaus A, Pestalozzi BC, Tebbutt NC, Li J, Kim TW, et al. Cediranib plus FOLFOX/CAPOX versus placebo plus FOLFOX/CAPOX in patients with previously untreated metastatic colorectal cancer: a randomized, double-blind, phase III study (HORIZON II). J Clin Oncol. 2012;30:3596-603.

91. Schmoll HJ, Cunningham D, Sobrero A, Karapetis CS, Rougier P, Koski SL, et al. Cediranib with mFOLFOX6 versus bevacizumab with mFOLFOX6 as first-line treatment for patients with advanced colorectal cancer: a double-blind, randomized phase III study (HORIZON III). J Clin Oncol. 2012;30:3588-95.

92. Batchelor TT, Mulholland P, Neyns B, Nabors LB, Campone M, Wick A, et al. Phase III randomized trial comparing the efficacy of cediranib as monotherapy, and in combination with lomustine, versus lomustine alone in patients with recurrent glioblastoma. J Clin Oncol. 2013;31:3212-8.

93. Ledermann JA, Embleton AC, Raja F, Perren TJ, Jayson GC, Rustin GJS, et al. Cediranib in patients with relapsed platinum-sensitive ovarian cancer (ICON6): a randomised, double-blind, placebo-controlled phase 3 trial. Lancet. 2016;387:1066-74.

94. Mullen MM, Kuroki LM, Thaker PH. Novel treatment options in platinum-sensitive recurrent ovarian cancer: a review. Gynecol Oncol. 2019;152(2):416-25.

95. Xu JM, Wang Y, Chen YL, Jia R, Li J, Gong JF, et al. Sulfatinib, a novel kinase inhibitor, in patients with advanced solid tumors: results from a phase I study. Oncotarget. 2017;8:42076-86.
96. Grillo F, Florio T, Ferrau F, Kara E, Fanciulli G, Faggiano A, et al. Emerging multitarget tyrosine kinase inhibitors in the treatment of neuroendocrine neoplasms. Endocr Relat Cancer. 2018;25:R453-66.

97. Yu S, Li A, Liu Q, Li T, Yuan X, Han X, et al. Chimeric antigen receptor T cells: a novel therapy for solid tumors. J Hematol Oncol. 2017;10:78.

98. Li J, Li W, Huang K, Zhang Y, Kupfer G, Zhao Q. Chimeric antigen receptor T cell (CAR-T) immunotherapy for solid tumors: lessons learned and strategies for moving forward. J Hematol Oncol. 2018;11:22.

99. Li Z, Song W, Rubinstein M, Liu D. Recent updates in cancer immunotherapy: a comprehensive review and perspective of the 2018 China cancer immunotherapy workshop in Beijing. J Hematol Oncol. 2018; 11:142.

100. Yi M, Jiao D, Xu H, Liu Q, Zhao W, Han X, et al. Biomarkers for predicting efficacy of PD-1/PD-L1 inhibitors. Mol Cancer. 2018;17:129.

101. Choueiri TK, Larkin J, Oya M, Thistlethwaite F, Martignoni M, Nathan P, et al. Preliminary results for avelumab plus axitinib as first-line therapy in patients with advanced clear-cell renal-cell carcinoma (JAVELIN renal 100): an openlabel, dose-finding and dose-expansion, phase 1b trial. Lancet Oncol. 2018; 19:451-60.

102. Motzer RJ, Penkov K, Haanen J, Rini B, Albiges L, Campbell MT, et al. Avelumab plus axitinib versus sunitinib for advanced renal-cell carcinoma. $N$ Engl J Med. 2019; (Epub ahead of print).

103. Kudo M. Systemic therapy for hepatocellular carcinoma: latest advances. Cancers (Basel). 2018;10(11). https://doi.org/10.3390/cancers10110412.

104. Giuliano S, Pages G. Mechanisms of resistance to anti-angiogenesis therapies. Biochimie. 2013;95:1110-9.

105. Hsieh JJ, Purdue MP, Signoretti S, Swanton C, Albiges L, Schmidinger M, et al. Renal cell carcinoma. Nat Rev Dis Primers. 2017;3:17009.

106. Chen Y, Chi P. Basket trial of TRK inhibitors demonstrates efficacy in TRK fusion-positive cancers. J Hematol Oncol. 2018;11:78.

107. Liu X, Qin S, Wang Z, Xu J, Xiong J, Bai Y, et al. Early presence of antiangiogenesis-related adverse events as a potential biomarker of antitumor efficacy in metastatic gastric cancer patients treated with apatinib: a cohort study.J Hematol Oncol. 2017;10(1):153.

108. Rini BI, Schiller JH, Fruehauf JP, Cohen EE, Tarazi JC, Rosbrook B, et al. Diastolic blood pressure as a biomarker of axitinib efficacy in solid tumors. Clin Cancer Res. 2011;17:3841-9.

109. Haas NB, Manola J, Dutcher JP, Flaherty KT, Uzzo RG, Atkins MB, et al. Adjuvant treatment for high-risk clear cell renal cancer: updated results of a high-risk subset of the ASSURE randomized trial. JAMA Oncol. 2017;3:1249-52.

110. Motzer RJ, Haas NB, Donskov F, Gross-Goupil M, Varlamov S, Kopyltsov E, et al. Randomized phase III trial of adjuvant pazopanib versus placebo after nephrectomy in patients with localized or locally advanced renal cell carcinoma. J Clin Oncol. 2017;35:3916-23.

111. Ravaud A, Motzer RJ, Pandha HS, George DJ, Pantuck AJ, Patel A, et al. Adjuvant sunitinib in high-risk renal-cell carcinoma after nephrectomy. N Engl J Med. 2016;375:2246-54.

112. Bruix J, Takayama T, Mazzaferro V, Chau GY, Yang J, Kudo M, et al. Adjuvant sorafenib for hepatocellular carcinoma after resection or ablation (STORM): a phase 3, randomised, double-blind, placebo-controlled trial. Lancet Oncol. 2015;16:1344-54.

113. Powles T, Sarwar N, Stockdale A, Sarker SJ, Boleti E, Protheroe A, et al. Safety and efficacy of pazopanib therapy prior to planned nephrectomy in metastatic clear cell renal cancer. JAMA Oncol. 2016;2:1303-9.

114. Ramjiawan RR, Griffioen AW, Duda DG. Anti-angiogenesis for cancer revisited: is there a role for combinations with immunotherapy? Angiogenesis. 2017;20:185-204. 